\title{
SLAVE MARKING BY THE SLAVE-MAKING ANT HARPAGOXENUS AMERICANUS (EMERY) (HYMENOPTERA: FORMICIDAE)
}

\author{
By Thomas M. Alloway and Gregory KeOugh ${ }^{1}$
}

\section{INTRODUCTION}

Colonies of the slave-making parasite Harpagoxenus americanus (Emery) raid nests of three host or "slave" species: Leptothorax ambiguus Emery, L. curvispinosus Mayr, and L. longispinosus Roger. The slavemakers attack a host-species target nest, cause the adults to flee, and carry the raided nest's brood of pupae, larvae and eggs back to the slavemakers' nest. Host-species workers which subsequently mature from captured brood become slaves, i.e. individuals which perform all the usual worker-ant functions for the slavemaker colony (Alloway 1979; Alloway \& Del Rio Pesdao 1983; Wesson 1939, 1940).

$H$. americanus raids are unusual among slave-making species in that very few target-colony adults are killed (Alloway 1979; Alloway \& Del Rio Pesado 1983). This comparative bloodlessness of $\boldsymbol{H}$. americanus raids can be viewed as an evolutionarily advanced means of husbanding a limited resource; and it may explain why $H$. americanus colonies are relatively abundant in most places where dense host-species populations occur, a situation which contrasts with the spotty, local distributions of other similar slave-making species (e.g. H. canadensis M. R. Smith and L. duloticus Wesson) that kill large numbers of adults in target nests and probably exterminate some raided colonies (Alloway 1979; Alloway \& Del Rio Pesado 1983; Del Rio Pesado \& Alloway 1983; Stuart \& Alloway 1982, 1983; Wesson 1939, 1940). Nevertheless, the survival of their slaves' parental colonies in close proximity to $H$. americanus nests poses a potential problem for the slavemaker. Alloway and Del Rio Pesado (1983) and Stuart (1985) have observed that host-species workers living in incipient $\boldsymbol{H}$. americanus colonies (nests where the only adult slavemaker is an $H$. americanus queen) are often

\footnotetext{
'Erindale College, University of Toronto, Mississauga, Ontario L5L 1C6, CANADA

* Manuscript received by the editor February 16, 1990.
} 
accepted as nestmates when they either enter spontaneously or are experimentally reintroduced to their parental colony; and these observations suggest that parental colonies might similarly accept offspring that had eclosed in more mature colonies containing $H$. americanus workers. However, such acceptance would provide the opportunity for the evolution of a host-species defense mechanism against the loss of workers caused by the raids of a common but non-lethal slavemaker such as $\boldsymbol{H}$. americanus. Natural selection should favor a tendency for slaves to search for and, whenever possible, rejoin their parental colony. Had such a host-species defense evolved and begun to spread through the population, natural selection might in turn have favored the evolution of a slavemaker countermeasure. The present study was designed to explore the possibility that $H$. americanus colonies containing slavemaker workers mark their slaves in some way which makes them unacceptable in their parental colonies.

\section{Materials AND Methods}

In the spring of 1988, nests of $H$. americanus and L. longispinosus, the species which $H$. americanus most commonly enslaves in eastern Canada, were collected in the regional municipalities of Halton and Peel, Ontario. Colonies were initially removed from their natural acorn nests and set up in $15 \times 150 \mathrm{~mm}$ plastic petri dishes which served as arenas for culture and observation. Each petri dish contained an artificial nest (Alloway 1979), a cotton-stoppered water bottle, and a small piece of waxed cardboard with a drop of Bhatkar and Whitcomb (1970) ant food on it. The food was replenished three times a week. Only L. longispinosus colonies which initially contained an even number of queens and at least 40 workers were employed in the experiment. In mid-June, each L. longispinosus colony which met these demographic criteria was divided in half; and the two halves were cultured separately under the same conditions in different $15 \times 150 \mathrm{~mm}$ plastic petri dishes.

Brood development was monitored in the $L$. longispinosus colonies. When nearly mature worker pupae appeared, some of the $L$. longispinosus colonies were paired with an $H$. americanus colony. Worker pupae from a single $L$. longispinosus colony were used to replace the slaves in a single $H$. americanus colony. The slaves which had been in the $\boldsymbol{H}$. americanus nests when they were collected were 
removed at the same time that the worker pupae were placed in the nests. The purpose of this manipulation was to produce $\mathrm{H}$. americanus colonies containing slaves from a single, known parental $L$. longispinosus colony.

The $\boldsymbol{H}$. americanus colonies were randomly divided into a "slavemaker-present" group and a "slavemaker-absent" group. In the slavemaker-present group, slaves and slavemaker adults were cultured together until two weeks after the last L. longispinosus worker had eclosed, at which time the acceptability of two slaves from each slavemaker-present nest was tested by placing them in L. longispinosus nests. One slave was tested in a nest of its parental colony; the other in a nest of another unenslaved $L$. longispinosus colony. In the slavemaker-absent group, the slavemaker adults were removed from the $H$. americanus nests one week after the eclosion of the last $L$. longispinosus worker; and slaves from these nests were likewise tested in their parental colony and in another L. longispinosus colony one week after the slavemakers had been removed. We reasoned that, if the slavemakers continually apply a mark to their slaves, slaves which had been living with slavemakers just prior to testing should be less acceptable in L. longispinosus nests than slaves which had been living apart from slavemakers during the previous week. Finally, as controls, we also tested the acceptability of unenslaved workers in the other half of their parental $L$. longispinosus colony and in a nest of another unenslaved $L$. longispinosus colony. The purpose of these controls was to validate the behavioural assay of worker acceptability and to determine whether the acceptability of slavemaker-deprived slaves differed from that of unenslaved $L$. longispinosus workers. In total, the six testing groups in the experiment can be viewed as constituting a $3 \times 2$ factorial design, the two variables being the three different "conditions of servitude" (slaves living with slavemakers, slavemaker-deprived slaves, and unenslaved workers) and the two "testing loci" (the parental colony and another unenslaved L. longispinosus colony).

A tethered-worker preparation was employed to determine the acceptability of workers in $L$. longispinosus nests. The day before a worker was to be tested, it was removed from the nest in which it had been living, anesthetized with ether, and tethered. After recovering from the anesthetic, the worker was returned to the nest where it had been living and remained there until just before the test. The 
tether consisted of a 2-cm single cotton fiber which had been dissected from a length of sewing thread. One end of the tether was tied around the worker's alitrunk between the middle and hind pairs of legs; the other end was glued to a $1-\mathrm{cm}$ insect-mounting point punched from a file card. Since the mounting point was too large to fit through the nest entrance, the net result of placing a tethered worker in a nest was to produce an individual which the nest's inhabitants could drag a short distance outside the nest entrance if they found it unacceptable, but could not entirely get rid of. The ants did not attempt to sever the fiber connecting a test worker to the mounting point.

At the beginning of a test, a tethered worker was placed inside its recipient nest; and the ensuing activity was observed under a dissecting microscope for $20 \mathrm{~min}$. Immediately and after 1, 5, 10, 15, and $20 \mathrm{~min}$, the following observations were recorded:

a. whether or not the tethered worker had been dragged outside the recipient nest;

b. the number of recipient-nest workers biting and/or stinging the tethered worker;

c. the number of fights among recipient-nest workers (i.e. fights not involving the tethered worker);

d. the number of recipient-nest workers carrying brood outside the nest.

Dragging a tethered worker outside the nest and biting and stinging it are indicators of the worker's rejection. The outbreak of fights among recipient-nest workers and carrying brood outside the nest are behaviors seen when an $\boldsymbol{H}$. americanus worker is inside a hostspecies nest (Alloway 1979, in press). To the extent that none of these behaviors occurred, a worker was considered to be accepted.

\section{RESULTS}

Initially, more unenslaved $L$. longispinosus colonies were available than $H$. americanus colonies; and new slaves failed to eclose in some $\boldsymbol{H}$. americanus nests. Thus, the total number of observations made of $L$. longispinosus test workers in the different experimental 
conditions varied considerably. We eventually obtained the following numbers of observations in the six experimental conditions:

Slaves living with slavemakers tested in their parental colony-35

Slaves living with slavemakers tested in another colony-24

Slavemaker-deprived slaves tested in their parental colony-27

Slavemaker-deprived slaves tested in another colony-26

Unenslaved workers tested in the other half of their parental colony-50

Unenslaved workers tested in another colony-56.

After being introduced into a nest of their own or another unenslaved $L$. longispinosus colony, some test workers were bitten and/or stung by varying numbers of workers; and some were dragged outside the nest entrance. However, in the present experiment, $L$. longispinosus test workers never excited brood evacuation and never provoked fighting among recipient-nest workers as $H$. americanus workers often do (Alloway 1979, in press).

As a measure of the tendency to drag test workers from recipient nests, we counted the total number of observation periods during which individual test workers were seen being dragged outside nests (possible range of 0 to 6). Preliminary examination of these data revealed that, although they were not normally distributed, they were skewed in the same direction in each experimental condition. In this circumstance, we followed the recommendation of Edwards (1960) and equalized the number of observations in each experimental condition before employing $3 \times 2$ factorial analyses of variance and post-hoc Tukey tests. The number of observations in each condition was reduced to 24 (the number of subjects in the experimental condition containing the fewest subjects) by randomly discarding data from experimental groups containing more than 24 subjects. Ten separate sets of analyses were performed with different randomly selected subsets of data. These analyses revealed that the only significant effect was the main effect of conditions of servitude (mean $F=6.92$, $d f=2 / 138, p<0.005$ ). Slaves living with slavemakers were dragged from nests a mean of 1.69 times; slavemakerdeprived slaves, a mean of 1.08 times; and unenslaved workers, a mean of 0.64 times. Tukey tests revealed that the only significant difference among these means was that between slaves living with slavemakers and unenslaved workers (mean $\mathrm{q}=5.10, \mathrm{k}=3$, $\mathrm{df}=$ $138, \mathrm{p}<0.005)$. 
Recipient-nest workers also manifested differing tendencies to attack (bite and/or sting) the different categories of test workers. These data were analyzed with $3 \times 2 \times 6$ analyses of variance in which the variables were respectively the 3 conditions of servitude, the 2 testing loci, and the 6 observation times, with observation time being treated as a repeated measure. Once again, to minimize testing bias with non-normal data skewed in the same direction in all conditions (Edwards 1960), the number of observations per cell was reduced to 24 by randomly discarding data for subjects in experimental groups containing more than 24 subjects; and 10 different analyses were performed with different randomly selected subsets of data.

A significant main effect of the repeated measure (mean $\mathrm{F}=$ 17.21 , df $=5 / 690, p<0.001)$ reflected the fact that the number of attacking recipient-nest workers generally increased as a function of time after the test workers' introduction. A significant main effect of testing locus (mean $\mathrm{F}=8.25, \mathrm{df}=1 / 138, \mathrm{p}<0.001$ ) indicated that the mean of 0.58 recipient-nest workers attacking test workers in parental nests was significantly less than the mean of 1.09 workers attacking test workers in nonparental nests. A significant main effect of condition of servitude (mean $F=5.44$, df $=2 / 138$, $\mathrm{p}<0.01)$ reflected significant differences among the three levels of this independent variable. The mean number of recipient-nest workers attacking test workers was 1.24 for slaves living with slavemakers, 0.73 for slavemaker-deprived slaves, and 0.64 for unenslaved workers. Tukey post-hoc tests revealed that significantly more recipient-nest workers attacked slaves living with slavemakers than attacked slavemaker-deprived slaves (mean $\mathrm{q}=3.51, \mathrm{k}=3$, $\mathrm{df}=138, \mathrm{p}<0.025$ ) or unenslaved workers (mean $\mathrm{q}=4.30, \mathrm{k}=3$, $\mathrm{df}=138, \mathrm{p}<0.005$ ). The difference between slavemaker-deprived slaves and unenslaved workers was not significant (mean $q=0.79$, $\mathrm{k}=3$, df $=138, \mathrm{p}>0.50$ ). A significant interaction between conditions of servitude and testing locus (mean $F=3.31$, $\mathrm{df}=2 / 138$, $\mathrm{p}<0.05$ ) arose primarily because unenslaved workers tested in their parental colonies elicited fewer attacks than unenslaved workers tested in nonparental colonies. Finally, a significant interaction between testing locus and the repeated measure (mean $F=2.59$, df $=5 / 690, p<0.05$ ) indicated that the number of attackers rose more steeply for workers tested in nonparental than in parental nests. 


\section{Discussion}

Slaves living with slavemakers were dragged from recipient nests more frequently and bitten and stung by more recipient-nest workers than unenslaved workers and bitten and stung more than slavemaker-deprived slaves. However, the response of recipient-nest workers to slavemaker-deprived slaves did not differ significantly from their response to unenslaved workers. These results indicate that something about living with slavemakers until just prior to testing makes slaves more unacceptable than unenslaved workers and that this effect dissipates during a one-week period when slaves are isolated from slavemakers.

The most likely source of this effect is the H. americanus workers. First, Alloway and Del Rio Pesado's (1983) and Stuart's (1985) observations that $L$. longispinosus workers which have been living with an $H$. americanus queen and brood are often accepted as nestmates in their parental colony seems to rule out the queen, brood, and nest as the source of the effect. Second, Alloway and Hare (1989) have shown that unenslaved L. longispinosus workers retrieve and care for $\boldsymbol{H}$. americanus larvae in preference to conspecific larvae, a finding which makes it seem even more unlikely that slavemaker larvae are the source of the effect. If the larvae were the source, one would expect host-species workers to reject rather than prefer slavemaker larvae. Third, H. americanus workers in L. longispinosus nests elicit a similar but stronger reaction than slaves produce. Workers not only bite and sting slavemaker workers and drag them outside the nest; they try to evacuate their brood (Alloway 1979, in press; Alloway \& Del Rio Pesado 1983). Fourth, workers in raided nests often attack nestmates which have touched an H. americanus worker (Alloway 1979, in press; Alloway \& Del Rio Pesado 1983), a fact which suggests that something which easily rubs off $\boldsymbol{H}$. americanus workers can cause target-nest workers to attack nestmates. Taken together, these considerations suggest as the most likely hypothesis that $\boldsymbol{H}$. americanus workers bear on the surface of their bodies a substance which also rubs off on their slaves. Slaves living in daily contact with slavemaker workers become contaminated with this substance, which makes them unacceptable as nestmates in their parental colonies.

At the beginning of this paper, we outlined reasoning which suggested that the marking substance may be an evolved adaptation of 
H. americanus, one of whose main functions is to prevent slave workers from deserting the slavemakers and returning to work in their nearby parental colonies. This evolutionary hypothesis can be tested by performing similar studies with other leptothoracine slavemaking species (e.g. Harpagoxenus canadensis and Leptothorax duloticus) that kill large numbers of target-colony workers during slave raids. If our functional hypothesis is correct, these slavemakers should not have evolved marking because these lethal raiders' slaves often lack living parental colonies to which they might return.

Stuart $(1985,1987,1988)$ has shown that unenslaved Leptothorax host-species colonies possess a collective nestmate recognition system. Individual workers produce colony-specific nestmate recognition cues, these cues are somehow shared among nestmates, and individuals are recognized as nestmates if they possess the combination of recognition cues characteristic of the colony. Basically the same recognition system undoubtedly also operates in $\mathrm{H}$. americanus colonies. We believe that the slave-marking system described here supplements the system described by Stuart $(1985,1987,1988)$ in a way which more effectively prevents the return of slaves to their parental nests.

\section{SUMMARY}

Leptothorax longispinosus ant workers were reared from pupae as slaves in nests of the slave-making ant Harpagoxenus americanus. Half the slaves lived in nests containing slavemaker adults until just prior to testing, while the other half lived in slavemaker nests from which the adult slavemakers had been removed one week before testing. The acceptability of these workers in L. longispinosus nests was tested by introducing them either to a nest of their unenslaved parental colony or to a nest of another unenslaved $L$. longispinosus colony. Slaves which had been living with slavemakers just prior to testing were attacked more than unenslaved workers and more than slaves which had been living in nests from which the slavemakers had been removed. Slaves which had been living without slavemakers were attacked no more than unenslaved workers. These findings suggest that $\boldsymbol{H}$. americanus chemically marks its slaves, that the mark prevents their return to their parental colonies, and that the mark dissipates with time. 


\section{ACKNOWLEDGEMENTS}

This research was supported by a grant to TMA from the Natural Sciences and Engineering Research Council (Canada). The data reported here were collected in partial fulfillment of the requirements for GK's B.Sc. thesis. We thank Akhilesh Leighl and Roger Mosquera for their assistance in collecting the ants and Robert Baker, James Beckwith, Alfred Buschinger, David Gibo, Jurgen Heinze, Andrew Sneddon, and Robin Stuart for their comments on the manuscript.

\section{REFERENCES}

Alloway, T. M.

1979 Raiding behaviour of two species of slave-making ants, Harpagoxenus americanus (Emery) and Leptothorax duloticus Wesson (Hymenoptera: Formicidae). Animal Behaviour 27: 202-210.

Alloway, T. M.

In press. Slave-species ant workers recognize slavemakers as enemies. Animal Behaviour.

Alloway, T. M., and Del Rio Pesada, M. G.

1983. Behaviour of the slave-making ant, Harpagoxenus americanus (Emery), and its host species under "seminatural" laboratory conditions (Hymenoptera: Formicidae) Psyche 90: 425-436.

Alloway, T. M., and Hare, J. F.

1989. Experience-independent attraction to slavemaker ant larvae in hostspecies ant workers (Leptothorax longispinosus; Hymenoptera: Formicidae). Behaviour 110: 93-105.

BhatKar, A., AND Whitcomb, W. H.

1970. Artificial diet for rearing various species of ants. Florida Entomologist 53: 229-232.

Del Rio Pesado, M. G., and Alloway, T. M.

1983. Polydomy in the slave-making ant, Harpagoxenus americanus (Emery) (Hymenoptera: Formicidae). Psyche 90: 151-162.

EDWARDS, A. L.

1960. Experimental design in psychological research. NY: Holt, Rinehart and Winston. vii $+398 \mathrm{pp}$.

STUART, R. J.

1985. Nestmate recognition in leptothoracine ants: Exploring the dynamics of a complex phenomenon. Ph.D. thesis, University of Toronto.

STUART, R. J.

1987. Individual workers produce colony-specific nestmate recognition cues in the ant, Leptothorax curvispinosus. Animal Behaviour 35: 1062-1069. 
StUART, R. J.

1988. Collective cues as a basis for nestmate recognition in polygynous leptothoracine ants. Proceedings of the National Academy of Science (USA) 85: 4572-4575.

Stuart, R. J., AND Alloway, T. M.

1982. Territoriality and the origin of slavery in Leptothoracine ants. Science 215: 1262-1263.

Stuart, R. J., AND Alloway, T. M.

1983. The slave-making ant, Harpagoxenus canadensis M. R. Smith, and its host species, Leptothorax muscorum (Nylander): Slave raiding and territoriality. Behaviour 85: 58-90.

Wesson, L. G., JR.

1939. Contributions to the natural history of Harpagoxenus americanus (Hymenoptera: Formicidae). Transactions of the American Entomological Society 35: 97-122.

WeSSON, L. G., JR.

1940. Observations of Leptothorax duloticus. Bulletin of the Brooklyn Entomological Society 35: 73-83.

ZAR, J. H.

1984. Biostatistical analysis. Englewood Cliffs, N.J.: Prentice Hall. xii + $718 \mathrm{pp}$. 

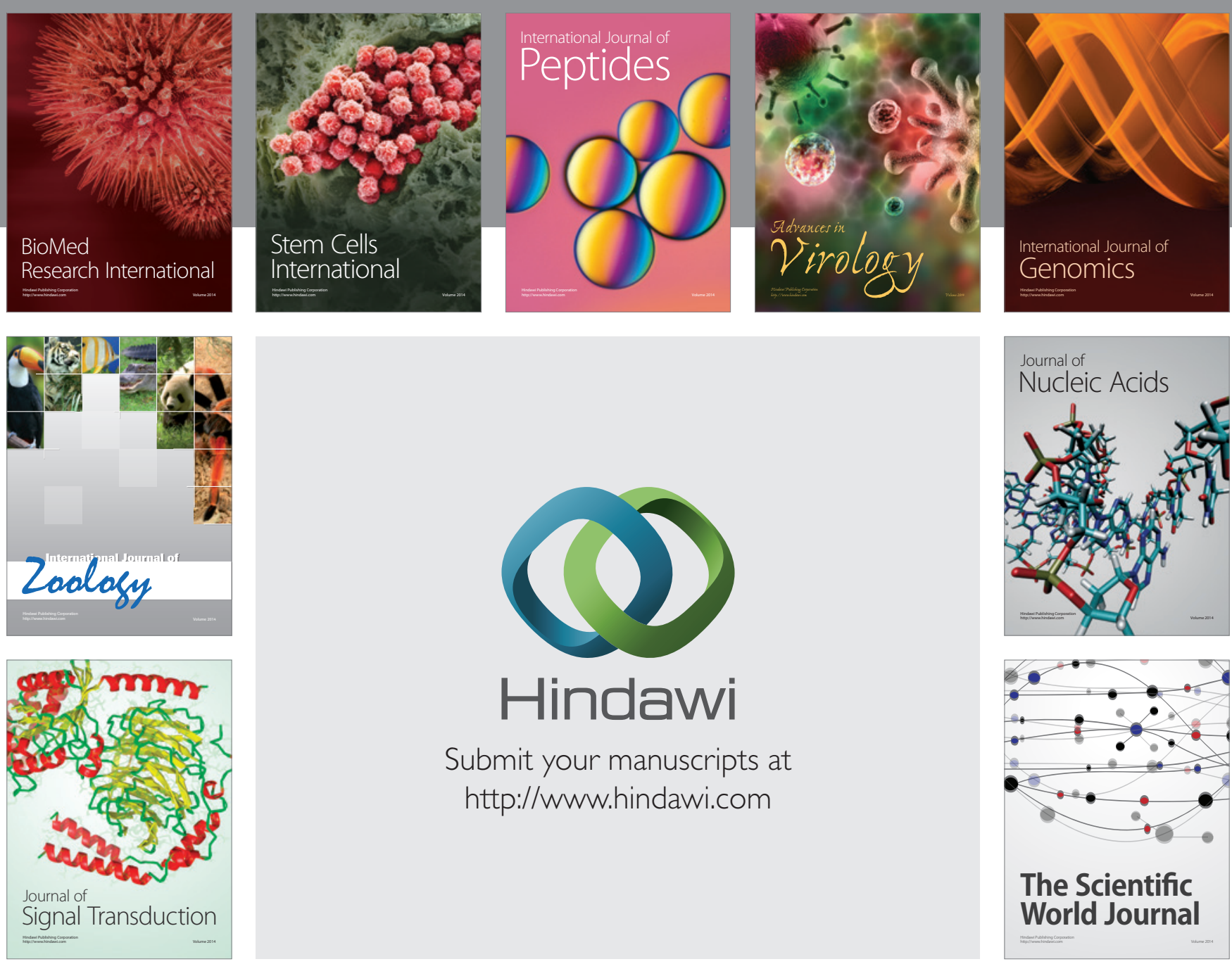

Submit your manuscripts at

http://www.hindawi.com
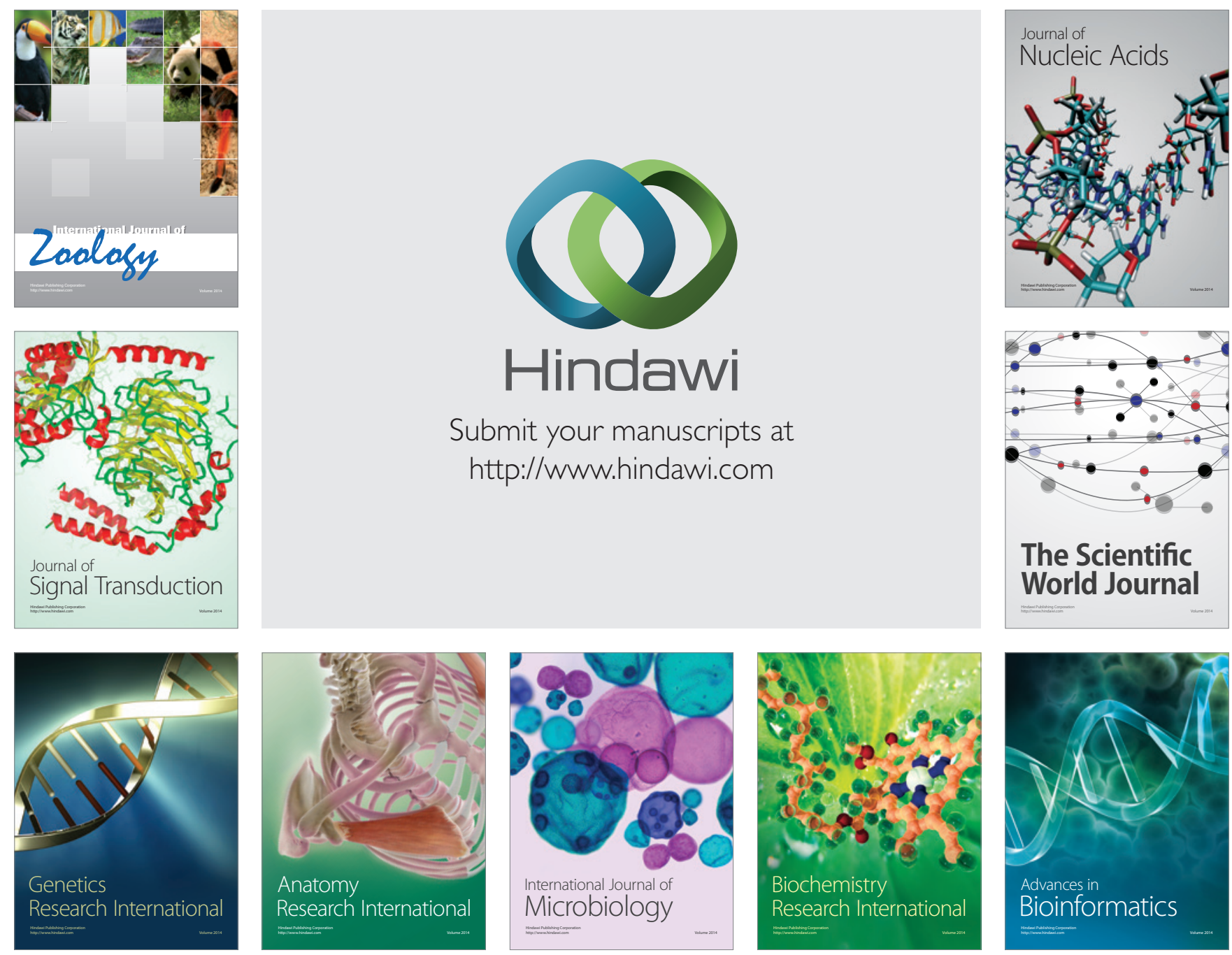

The Scientific World Journal
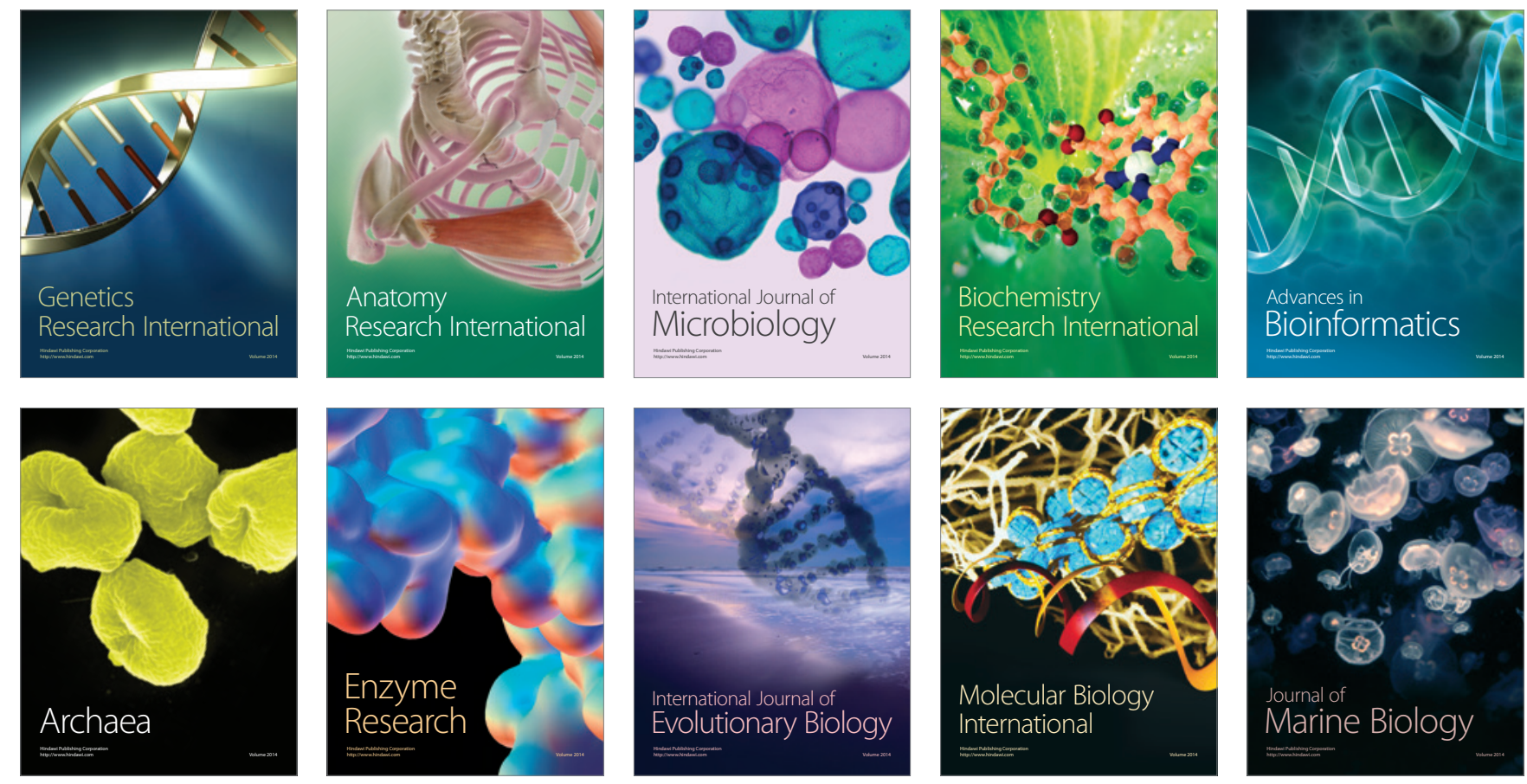